\title{
Saúde mental e subjetividade no trabalho de uma guarda municipal: estudo em psicodinâmica do trabalho
}

\author{
Tatiana Cardoso Baierle e Álvaro Roberto Crespo Merlo \\ Universidade Federal do Rio Grande do Sul
}

\begin{abstract}
Este artigo é resultado de pesquisa de mestrado que teve por objetivo compreender as implicações da reestruturação da guarda municipal de uma capital brasileira sobre a dinâmica saúde/sofrimento mental de seus trabalhadores. A fundamentação teórica e metodológica empregada foi a psicodinâmica do trabalho, procurando identificar as estratégias defensivas desenvolvidas pelos trabalhadores para evitar o adoecimento. No desenvolvimento da pesquisa foi possível constatar que o atual período da instituição é um tempo de transformação, que interfere na organização do trabalho, na subjetividade e na saúde mental de seus servidores. $\mathrm{O}$ sofrimento provocado pelo trabalho é amortecido pela cooperação mútua, pela possibilidade do uso da inteligência astuciosa e pelo reconhecimento advindo de uma atuação com maior visibilidade. Na busca da promoção da saúde mental no trabalho, mostra-se importante incrementar os espaços institucionais de reflexão e discussão sobre o atual papel do guarda municipal na sociedade.
\end{abstract}

Palavras-chave: Guarda municipal, Psicodinâmica do trabalho, Psicologia social, Saúde do trabalhador, Saúde mental.

Mental health and subjectivity at the work of a municipal guard: a study in psychodynamic of work

This article resulted from a master's degree research that had as objective to understand the implications of reorganization of a municipal guard from a Brazilian capital on the dynamic health/mental suffering of its workers. The theoretical and methodological recital used was the psychodynamic of work, looking for to identify the defensive strategies developed by the workers to prevent illness. In the development of the research it was possible to evidence that the current period of the institution is a transition time, which intervenes with the organization of work, the subjectivity, and the mental health of its servers. The suffering produced at work is cushioned by the mutual cooperation, the possibility of the use of astuteness intelligence and by the recognition happened of a performance with bigger visibility. In the search of the promotion of the mental health in the work one reveals important to develop the institutional spaces of reflection and quarrel on the current paper of the municipal guard in the society.

Keywords: Municipal Guard, Psychodynamic of work, Social psychology, Health of workers, Mental health.

\begin{abstract}
A saúde mental não é certamente o bem-estar psíquico. A saúde é quando ter esperança é permitido. (...) $\bigcirc$ que faz as pessoas viverem é, antes de tudo, seu desejo. (...) $\mathrm{O}$ verdadeiro perigo existe quando não há mais desejo, quando ele não é mais possível (Dejours, 1986, p. 9).
\end{abstract}

\section{Introdução}

s guardas municipais não são novidade no Brasil, entretanto, parecem ser
(re)descobertas a partir da análise de alternativas à problemática das políticas de
segurança pública. Os trabalhadores desse serviço público municipal de segurança passaram a
desempenhar diferentes atividades, resultando na construção de um novo status social e 
reconhecimento profissional. Frente a esse cenário torna-se imperativo que seja dedicada especial atenção a essas instituições e a seus trabalhadores.

O objetivo deste estudo consistiu em conhecer as implicações da reestruturação da Guarda Municipal de Porto Alegre sobre a dinâmica saúde/sofrimento mental de seus trabalhadores. O trabalho foi tomado como eixo norteador da pesquisa, pelo lugar de centralidade que ocupa na vida contemporânea, atravessando a estrutura socioeconômica, cultural e ética da sociedade ocidental. Conseqüentemente, marcando a subjetividade de todos, balizando modos de ser e estar no mundo.

Com essa premissa, a condução da pesquisa foi fundamentada na abordagem da psicodinâmica do trabalho, na busca do entendimento acerca da dinâmica saúde/sofrimento mental no trabalho do guarda municipal. Os sujeitos da pesquisa, realizada no período de julho a dezembro de 2006, foram servidores públicos municipais que atuam nesta instituição. Sendo a escolha por um método qualitativo, o objetivo não foi buscar um perfil estatístico, mas realizar uma análise compreensiva dos efeitos do trabalho na guarda municipal sobre a subjetividade e a saúde mental de seus servidores.

Escolhemos a Guarda Municipal de Porto Alegre (GMPA) pela antigüidade da Instituição (115 anos), por ser a guarda de uma capital e devido ao processo de reestruturação que atravessa. Por reunir essas características acreditamos que o estudo desenvolvido e os resultados obtidos não são específicos dessa instituição, refletindo o atual cenário das guardas municipais no Brasil.

De acordo com Soares (2005), a atuação local na gestão da segurança é uma tendência não apenas do Brasil, mas mundial. Está justamente na proximidade da população e na penetração capilar do governo municipal sua vantagem. Dessa maneira é possível aprofundar os instrumentos de controle social, de articulação com a sociedade e de consideração às peculiaridades regionais.

A questão da promoção da segurança, da prevenção do crime e das conflitualidades em âmbito local, não é tarefa nova para os municípios. Como destaca Dias Neto (2005), a prevenção sempre foi praticada pelos municípios, com caráter indireto, através de assistência social, saúde e educação. A inovação está em tratar esse campo não como subproduto, mas como ação transversal das políticas públicas.

A Constituição Federal de 1988, no capítulo que versa sobre a segurança pública, no artigo 144, abre a discussão da participação dos municípios na segurança pública, estabelecendo que eles podem constituir guardas municipais para proteção de seus bens, serviços e instalações. Contudo, as normas constitucionais estabelecem regras, valores ou princípios, que devem ser levados em consideração na elaboração das leis. Porém, enquanto a lei não existir, não é possível estabelecer com clareza quais serão as atribuições e os limites de atuação, enfim, o sentido concreto da norma. Portanto, a constituição estabelece as normas gerais, mas são as leis que irão dizer como as suas regras funcionarão.

No caso das guardas municipais, a regulamentação deve ser feita no âmbito dos municípios. Por essa razão, encontramos muitas diferenças na estrutura e atuação das guardas de um município para outro. Existem inúmeras guardas municipais que não têm metas claras, padrões comuns de atuação, organograma, hierarquia ou gerenciamento de informações. As guardas municipais são referidas no Plano Nacional de Segurança Pública como o único instrumento especificamente voltado para a segurança no âmbito municipal. Entretanto, como alerta Guindani (2005), muitas guardas municipais ainda são formadas dentro de um perfil claramente militarizado, voltado para a repressão.

$\mathrm{Na}$ busca de uma regulamentação nacional comum para as guardas municipais, a Secretaria Nacional de Segurança Pública (SENASP) tem destinado particular atenção a estas instituições. Nessa perspectiva, foram elaborados no ano de 2005: a "Pesquisa do perfil 
organizacional das guardas municipais" e a "Matriz curricular nacional para a formação de guardas municipais".

O desafio está em construir ações que viabilizem políticas públicas de segurança em âmbito local, com caráter multidisciplinar, congregando ações sociais e governamentais. Voltadas não apenas para a punição, mas para respostas integradas de prevenção e de intervenção, que busquem a promoção da defesa dos direitos e da cidadania. Nesse sentido, pensar ações de valorização profissional e de promoção e prevenção da saúde mental dos operadores da segurança pública, incluindo aqui os guardas municipais, é fundamental.

\section{Metodologia de pesquisa em psicodinâmica do trabalho}

A pesquisa em psicodinâmica do trabalho (Dejours, 1992) centra a investigação na normalidade e não na patologia, procurando compreender como os trabalhadores conseguem não adoecer ou enlouquecer frente às pressões cotidianas. Com isso, busca romper com o modelo causal médico-biológico, balizado pela doença, reforçando os mecanismos de luta e de resistência desenvolvidos pelos trabalhadores, que se traduzem nas estratégias defensivas.

A metodologia em psicodinâmica do trabalho prevê diferentes fases de desenvolvimento para a pesquisa: formação de grupo de pesquisadores, pré-pesquisa, pesquisa e validação. Descrevemos a seguir como se deu o desenrolar deste trabalho.

\section{Formação do grupo de pesquisadores}

A formação de um grupo de pesquisadores, preferencialmente de áreas de atuação distintas, para o acompanhamento da pesquisa é uma importante premissa. Nesse sentido buscou-se contemplar a metodologia tendo como grupo de apoio à pesquisa: o orientador ${ }^{1}$, uma fisioterapeuta ${ }^{2}$, uma administradora ${ }^{3}$, um aluno de graduação em psicologia $^{4}$ e uma aluna de graduação em psicologia formada em direito 5 . O grupo alternou-se acompanhando a pesquisadora responsável (psicóloga e mestranda do PPGPSI da UFRGS) na realização das visitas e das entrevistas referentes à pré-pesquisa e no acompanhamento dos grupos referentes à pesquisa propriamente dita. As reuniões desse grupo para discussão do material produzido no campo foram realizadas sistematicamente, de acordo com o fluxo da pesquisa.

\section{Pré-pesquisa}

O objetivo da pré-pesquisa é conhecer o campo, reunir informações sobre o processo de trabalho e a estrutura da organização. Nessa etapa foram realizadas visitas a diferentes setores de trabalho da Guarda Municipal de Porto Alegre, com a finalidade de obter uma maior compreensão sobre o cotidiano de trabalho e as diferentes funções exercidas pelos guardas municipais. Nessa etapa também foram realizadas entrevistas com chefias e gestores, investigação documental, consulta à Gerência de Saúde do Servidor Municipal (GSSM) e à Gerência de Acompanhamento Funcional (GEAF) da Prefeitura Municipal de Porto Alegre.

\footnotetext{
1 Médico do trabalho.

2 Mestranda em Engenharia de Produção pela UFRGS.

3 Aluna especial do PPGPSI da UFRGS.

4 A participação na pesquisa consistiu em seu estágio curricular em psicologia do trabalho.

5 Bolsista de iniciação científica, CNPq.
} 
Em razão da amplitude do efetivo, das funções e dos postos de trabalho da instituição, optou-se por trabalhar com as funções que estavam mais diretamente vinculadas às transformações decorrentes da reestruturação da Guarda Municipal: patrulheiros, motoristas, operadores da Central de Operações, motociclistas e fiscais. ${ }^{6}$ Os trabalhadores participaram da pesquisa por sua livre opção?

\section{Pesquisa}

A metodologia de pesquisa propõe a realização de uma série de encontros com o grupo de trabalhadores em local identificado com seu trabalho. Os encontros dos grupos aconteceram no refeitório da sede da Guarda Municipal e na Sede do Grupo de Apoio (GAPO). Os locais de realização dos encontros foram escolhidos pelos próprios trabalhadores, sendo respeitada a indicação. Durante os encontros do grupo esses locais foram destinados especificamente para a finalidade da pesquisa, não havendo circulação de outras pessoas e sendo resguardado o sigilo.

Os encontros desenvolveram-se com duração média de uma hora e meia e periodicidade semanal. Foram realizados ao todo 18 encontros em grupo, com participação total de 38 guardas, homens e mulheres, reunindo de 4 a 10 participantes por encontro. Apesar de não previsto pela metodologia, foram feitas gravações das discussões para posterior transcrição, com o objetivo de não perder acontecimentos significativos do grupo. Nos encontros procurou-se manter sempre o procedimento de haver pelo menos dois pesquisadores. Como forma de registro complementar, também foi elaborado diário de campo, com comentários dos pesquisadores envolvidos.

\section{Validação e refutação}

A etapa de validação e refutação propõe a realização de reunião com os sujeitos participantes da pesquisa após a análise inicial dos dados. O objetivo é constituir um espaço de participação e de apropriação por parte dos trabalhadores da produção de conhecimento construída na pesquisa. Dessa maneira, os sujeitos têm a oportunidade de concordar ou discordar da análise que está sendo realizada, sugerindo alterações antes da escrita do documento final. Essa devolução dialogada foi realizada nos últimos três encontros com o grupo. Essa forma de proceder deu-se em função do grupo de pesquisa realizar reuniões sistemáticas para proceder à análise do material produzido. Nesse momento os guardas opinaram e discutiram os apontamentos realizados pelos pesquisadores, as categorias elegidas e a análise dos dados. Os pontos de discordância foram debatidos e discutidos visando um entendimento comum e o aperfeiçoamento da escrita final, de modo a traduzir sua vivência.

\section{Caracterização da instituição}

A GMPA foi criada em 1892 e em sua existência atravessou diferentes períodos políticos e organizativos. Seu efetivo, em dezembro de 2006, era formado por 598 guardas municipais. Tem como instrumentos de trabalho a arma de fogo, o bastão PR-24, algemas e rádio transceptor portátil. $\mathrm{O}$ número de mulheres corresponde a $6 \%$ do quadro (realidade que segue o perfil encontrado nas polícias militar e civil do Brasil).

6 Os guardas que ocupam essas funções correspondem a 31\% do efetivo total da GMPA.

$7 \mathrm{O}$ objetivo e o método da pesquisa foram esclarecidos aos trabalhadores que, após completo entendimento e concordância, assinaram Termo de Consentimento Livre e Esclarecido. 
Entre o efetivo, 66\% dos guardas têm mais de 40 anos de idade. Em razão da perda das vantagens da remuneração, que só são obtidas na ativa, muitos guardas retardam a aposentadoria, permanecendo em serviço até a idade máxima permitida por lei ou até o limite de sua saúde.

O vencimento básico do guarda municipal pode ser considerado baixo ${ }^{8}$, sua remuneração acaba sendo acrescida de uma série de vantagens pecuniárias que o aumentam (chegando em média a 1.600 reais). A composição salarial inclui o vencimento básico, a periculosidade, o Regime de Tempo Integral (RTI), as horas extras, o vale alimentação, o adicional noturno, quando lotado nesse turno, e a função gratificada quando em cargo de chefia.

Conseqüência também dessa política salarial, não é incomum a insistência dos guardas em trabalhar mesmo quando doentes, para evitar a redução de horas extras e do vale alimentação. É importante destacar que 63\% do efetivo encontra-se lotado no turno da noite.

Em 1997 ocorreu a primeira mudança significativa no funcionamento da instituição, com a implantação do Sistema de Alarme Eletrônico (SAE). Com isso, muitos guardas foram deslocados do trabalho noturno para o diurno e a GMPA ampliou sua capacidade de atendimento. Esse processo de reestruturação foi intensificado a partir de 2002, com a realização de concurso público, após dez anos sem ingresso de novos servidores.

Em janeiro de 2003, com a criação da Secretaria Municipal de Direitos Humanos e Segurança Urbana (SMDHSU), que assume a gestão da Guarda Municipal, a instituição passa a ter maior visibilidade e assumir funções diferenciadas. Entretanto, essa fusão não contou com a participação dos guardas municipais, repercutindo negativamente na relação estabelecida entre os setores da guarda e dos direitos humanos, dentro da secretaria.

Atualmente, a GMPA atende mais de 300 setores (secretarias municipais, escolas, praças, postos de saúde e outros), distribuídos em nove regióes geográficas da cidade, denominadas Áreas Operacionais. Em cada Área Operacional existe uma sub-sede e um chefe de área, que é responsável pelo gerenciamento de setores e guardas da região. $\mathrm{O}$ atendimento prestado pela Guarda Municipal divide-se em: fixo (prestado diretamente nos prédios), volante (serviço de patrulha executado por viaturas e motocicletas) e Sistema de Alarme Eletrônico (monitoramento realizado pela Central de Operações, COGM).

A GMPA não possui plano de carreira específico, estando sujeita ao mesmo regime de trabalho dos demais servidores estatutários da prefeitura. A estrutura de cargos e funções opera na informalidade, estando defasada em relação ao trabalho desenvolvido.

Tanto a administração da Prefeitura Municipal de Porto Alegre, quanto os guardas municipais entendem que a exigência formal de escolaridade para ingresso, correspondente à sexta série do ensino fundamental, é um equívoco, não condizendo com as atuais demandas e funções da guarda. Apesar disso, apenas $16 \%$ do efetivo possui ensino fundamental incompleto.

Em termos de infra-estrutura de trabalho, a instituição apresenta muitas carências. Em comum entre sede e sedes de área, a precariedade de estrutura física e de equipamentos. Característica acentuada ao extremo nos setores que contam com atendimento fixo. A improvisação criativa dos próprios guardas é o que permite acomodar em espaços mínimos cozinha, banheiro, vestiário e setor administrativo, via colaboração individual e coletiva, com móveis e eletrodomésticos comprados em conjunto ou trazidos de suas próprias casas.

Essa condição de precariedade estrutural não é exclusiva da guarda. Praticamente todas as secretarias e setores da prefeitura enfrentam essa mesma realidade. Parece ser uma característica do serviço público nos dias que correm, com raras exceções. Porém, no caso da

8 Em novembro de 2006 correspondia a R \$ 481,90. 
GMPA, essa situação parece ser agravada pela falta de prédios próprios. As causas são múltiplas, mas talvez o essencial tenha a ver com a ausência de autonomia burocrática e a submissão à lógica da busca de resultados imediatos por parte de cada governo que chega ao poder, mesmo quando consegue reeleger-se.

Em levantamento realizado pela GSSM, no ano de 2004, sobre os afastamentos para tratamento de saúde na GMPA, foram apontadas 260 Licenças para Tratamento de Saúde (LTS), resultando num total de 5.120 dias de afastamento. As patologias mais freqüentes são doenças do aparelho respiratório, doenças do sistema osteomuscular e traumatismos.

O uso abusivo de álcool e drogas é assinalado tanto pela GSSM, como pelo comando da GMPA como o principal problema de saúde encontrado entre os guardas municipais. Contudo, essa realidade não se traduz no levantamento dos afastamentos. A explicação para essa questão está no fato de que alcoolismo e drogadição não geram LTS, mas um alto índice de absenteísmo. Além disso, muitas vezes o guarda entra em licença saúde por patologias secundárias resultantes do abuso de álcool e drogas, que mascaram o real problema.

Embora não se possa generalizar, a grande maioria das funções de ponta (que sofrem diretamente o impacto da reestruturação) está sendo desempenhada por guardas que ingressaram na PMPA através do último concurso realizado em 2002. Isso fez com que surgisse uma espécie de divisão entre guardas antigos e novos. Entretanto, essa segmentação não se restringe ao tempo de trabalho, parece mais indicar um diferencial sobre a concepção do trabalho na Guarda Municipal.

Os novos apostam em uma guarda mais atuante, mais próxima da população e com diversidade de funções. Correspondem aos guardas que atuam em funções diferenciadas, como motoristas, patrulheiros, motociclistas, pessoal da sede da GMPA, plantões, chefes de área, e operadores da COGM. São os mais diretamente expostos às mudanças de atuação geradas pela reestruturação da GMPA. São esses servidores que estão atuando e influindo nessas transformações, tendo possibilidade de troca com os colegas e espaço de reconhecimento.

Compõem o grupo antigo, de modo geral, os guardas que atuam no atendimento fixo: em prédios, escolas e secretarias. Esse grupo caracteriza-se pelo maior tempo de serviço na guarda municipal, por encontrar-se afastado das transformações em andamento e por apresentar maior desconfiança com relação às mudanças na organização do trabalho.

O regime de trabalho oficial é de plantões de doze horas de trabalho por trinta e seis de descanso. De forma alguma é o que acontece no dia-a-dia. Encontramos as mais diversas jornadas de trabalho: guardas que cumprem expediente durante a semana e hora extra nos finais de semana, guardas que trabalham vinte e quatro horas, guardas que trabalham todas as noites, dentre outros.

A extensa jornada de trabalho deve-se ao constante crescimento da demanda por serviços da Guarda Municipal, enquanto o efetivo continua estacionado, não a acompanhando. Para suprir essa defasagem a solução encontrada é complementar a carga horária normal com horas extras. Funcionamento que ocorre a tantos anos que se encontra incorporada à cultura da instituição. Com isso, os guardas acabam sempre tendo um número de horas extras a cumprir por mês (atualmente são 120 horas extras) e o dinheiro extra acaba incorporado como salário. Essa característica traz inúmeras conseqüências em termos de saúde e organização da vida. 


\section{Discussão}

O trabalho pode ser fator estruturante da pessoa e/ou fonte de sofrimento. Como ensina Dejours (2005): "não há neutralidade do trabalho diante da saúde mental" (p. 35). O sofrimento no trabalho pode atuar em duas direções distintas, de mobilização criativa ou de acomodação e alienação. Quando a serviço da última situação, os sujeitos constroem defesas, que acabam por neutralizar o sofrimento, mas também os sentimentos de indignação, confiança e a solidariedade.

A extensa jornada de trabalho, de doze horas diárias, mais as horas extras fazem com que os guardas municipais passem, de fato, a maior parte do tempo no trabalho. Mas, ao invés dessa questão surgir como um problema, os trabalhadores justificam afirmando que já se acostumaram e que em outros postos de trabalho poderia ser ainda pior (citam a brigada militar e a segurança privada). São as 120 horas extras que melhoram consideravelmente o salário, então, os prejuízos em termos de saúde e vida pessoal parecem ficar em segundo plano. Isso faz com que muitos guardas trabalhem além do seu limite para não perder salário.

Por mais que se acostume, quando vê, não acostumou. Às vezes fico até tonto, dobro muito trabalho. Mas dá pra conciliar, porque compensa no final do mês. O final do mês compensa todo o esforço.

Outra questão relativa à jornada de trabalho que é peculiar à Guarda Municipal é o trabalho em turnos. Característica que também é encontrada nas polícias, nos operadores de usinas e na área da saúde. O prejuízo à vida social e familiar é somado ao desgaste físico e mental provocado pela inversão do funcionamento diurno pelo noturno. Diferentes autores (Amador, 2002; Dejours, 1999; Minayo, 2003; Spode, 2004; Tittoni, 1994) apontam que o trabalho em turnos acarreta não apenas distúrbios físico-biológicos, mas também conseqüências psicológicas e sociais, atingindo a vida familiar e desencadeando reações de agressividade e de intolerância devidas ao desgaste físico e emocional.

A carga horária é muito extensa. Acabei me separando por isso. A carga horária é de doze horas por dia e mais o plantão à noite. Quer dizer, a família acaba. Hoje um dia sim, outro também, são doze por doze.

A jornada de trabalho da GMPA também se diferencia por ser ininterrupta, ou seja, funciona todos os dias da semana, vinte e quatro horas. Isso implica em um descompasso com feriados, finais de semana e datas festivas.

Com essa parte eu me acostumei. No começo chegava a me cair as lágrimas, todo mundo festejando e eu ali, fechado, olhando para a rua.

Os maiores problemas de saúde são o alcoolismo e a drogadição. É um sintoma que se reproduz a partir do modelo das polícias. Parece tratar-se de uma busca por entorpecimento frente a uma realidade por demais ansiogênica e dolorosa. De acordo com os relatos, essa é uma situação que se demonstra agravada para os guardas que prestam atendimento fixo. Isso porque nos postos "móveis" ainda é possível encontrar respaldo e reconhecimento nos colegas, realizar trocas e ter um senso de coletivo.

A grande verdade é que, trabalhar de noite dentro de um setor, tem doze horas contigo mesmo, só bêbado, fumando um ou dormindo o tempo todo.

Entre os equipamentos utilizados pela GMPA nenhum é mais polêmico e simbólico do que a arma de fogo. De fato, a GMPA sempre utilizou arma de fogo como equipamento de 
trabalho. Entretanto, não havia respaldo legal para o porte de arma pelos trabalhadores das guardas municipais, situação que veio a ser solucionada com o Estatuto de Desarmamento9. Por meio da imprensa local esse ponto ganhou destaque sendo foco de discussão pela população.

Para os guardas essa não é uma questão tranqüila. Pauta de muitas discussões, não é possível afirmar que exista uma definição ou uma tendência quanto à utilização da arma de fogo. Alguns defendem o uso em todos os setores e postos de trabalho, outros apenas em determinadas funções. Curiosamente o pessoal mais operacional muitas vezes acaba sendo a voz contrária ao armamento. Talvez por vivenciar em seu cotidiano de trabalho as agruras da rua, sabem que a arma é o último recurso a ser utilizado e que muitas vezes pode ser mais um atrativo ao criminoso e um risco para o guarda.

Para a saúde mental muda muito. O estresse é muito maior de trabalhar com a arma. Entra decisão de tiro, entra o teu comportamento, entra a tua atuação, como vais te posicionar e sacar uma arma em público.

A psicodinâmica do trabalho valoriza a brecha existente entre o trabalho prescrito e o trabalho real. Isso porque é justamente nesse espaço que é possível a invenção criativa pelos trabalhadores. No caso da GMPA, encontramos uma distorção em relação a esse aspecto, pois a brecha encontra-se dilatada pela má definição do prescrito. A lacuna de prescrição no trabalho da GMPA dá-se por duas vias: a ausência de um plano de carreira, que resulta em uma estrutura organizacional conflituosa, e a falta de uma instrução normativa para o trabalho.

A carência de um plano de carreira específico para a GMPA é apontada pelos guardas como fator de desmotivação, pois podem ser simplesmente guardas por toda a carreira. Não há garantias de que uma melhor qualificação leve a um posto diferenciado. Também não há garantias de que uma vez alcançado um posto de chefia não se retorne à condição de subordinado.

Já te falei: hoje estou chefe de equipe, amanhã não sei, daqui a pouco estou num setor, lá no portão. Então, tem que ver isso aí, quem está em cima daqui a pouco está lá em baixo. (...) A gente costuma brincar que "estás" chefe, não "és" chefe.

A ausência de uma normatização sobre os procedimentos a serem seguidos pelos guardas gera a falta de padronização nas ações. Essa falha na prescrição faz com que o espírito de corpo seja quebrado de alguma maneira. O eu se sobressai, é o modo como eu trabalho e não o modo como a guarda trabalha.

Os guardas referem que seu trabalho não apresenta uma produção concreta, algo que ao final do dia possa ser visualizado e mensurado. Isso dificulta o reconhecimento, pois o trabalho da vigilância não aparece, a menos que ocorra algum problema. Também por não exigir materiais concretos, o guarda é colocado em locais precários em termos de atendimento das necessidades básicas do trabalhador. Uma vez que para fazer a segurança, "só é necessária a pessoa do guarda".

O nosso trabalho não é como o pedreiro, que coloca um tijolo, mais outro tijolo, mais outro tijolo e no fim do dia tem uma parede. O nosso trabalho não aparece.

O trabalho pode não produzir uma parede no final do dia, mas produz subjetividade. Não se é guarda municipal apenas durante as doze horas de trabalho. Essa construção se 
estende para a vida como um todo. A contaminação do tempo fora do trabalho é intensa, incrementando características de desconfiança.

Antes eu andava pela rua bem desligado, agora não. Eu sempre estou olhando o que está na frente, estou bem mais atento do que eu era antes. Às vezes quando retorno para casa, de noite, eu vou fazendo patrulhamento, olhando para o lado.

A situação do imprevisto no cotidiano de trabalho aparece como fator de pressão e de estresse. Apesar de existir um planejamento das ações, sempre pode acontecer o inesperado. Dessa maneira o guarda deve estar o tempo todo em alerta, situação que gera intenso desgaste. Mas, também, é justamente a adrenalina e o imprevisto do trabalho que atraem. É essa emoção do dia-a-dia que faz com que o trabalho "vicie".

[O que faz gostar de trabalhar na Guarda?] A adrenalina! Adrenalina, a espera, nunca se sabe o que vai dar. A inconstância do dia, um dia nunca é igual ao outro.

O risco existe e é real no cotidiano de trabalho. Por ser guarda municipal, isso não significa que enfrente situações mais fáceis ou menos perigosas do que a polícia. A morte em serviço é uma probabilidade. O risco é visto como inerente à função, ser segurança significa ser o primeiro anteparo.

Tem que ter um psicológico forte para agüentar. Nós estamos preparados para o quê? Para esta ação, sermos assaltados, de tentar evitar se der, mas somos a primeira barreira. Ou passam por cima de nós ou conseguimos barrar, então é essa a condição de ser segurança.

O sentimento de medo está presente entre os servidores da GMPA. Entretanto, é difícil falar sobre o medo e mais ainda sobre o risco de morte. Alguns admitem e chegam a apontar o medo como fator saudável, fator de limite na ação. Outros negam, como mecanismo de defesa frente à ansiedade provocada pelas situações do cotidiano de trabalho. Admitir o medo e o risco poderia implicar em uma paralisação da ação e conseqüentemente do trabalho.

Tinha que me impor para não sentir medo. (...) Então, assim, ó, medo, essa palavra não existe em mim, pode existir o pequeno receio no enfrentar, mas é um receio, não chega a ser medo.

As estratégias coletivas de defesa são ativadas na busca de driblar a ansiedade gerada pelo trabalho de risco. Outro destaque cabe ao pensamento mágico voltado ao misticismo. A crença de que a GMPA e seus trabalhadores estão protegidos pelos "deuses":

Só não acontecem coisas piores com a Guarda porque tem um grande anjo com as asas bem abertas aqui em cima da viatura.

O fato dos guardas comprarem móveis, adaptarem e inventarem no ambiente de trabalho pode ser entendido como zelo. Sem esses procedimentos, que aparentemente destoam da imagem construída pelo senso comum sobre o comportamento do servidor público, o trabalho da guarda não seria possível.

Já cansei de pagar lâmpadas, mas por que vou fazer isso? Pelo pessoal que trabalha à noite.

(...) Estou trocando a lâmpada, não é meu serviço, mas é para o pessoal da noite.

E esses materiais que vocês vêem aqui para treinamento. É a questão da amizade. O que nós temos aqui: micro, fogão, geladeira foi cada um que conseguiu. Um trouxe uma mesa, a bicicleta é de outro, mas mantemos uma academia aqui dentro. 
A vinculação com o colega é fator chave para o trabalho da GMPA. É com o colega que se conta no momento de enfrentamento, ele está ali nas situações boas e ruins. Ao mesmo tempo em que esse funcionamento traz um sentido de coesão ao grupo, também faz com que algumas questões sejam encobertas pelos próprios guardas.

Nesse sentido, o fluxo de comunicação aparece como estratégia defensiva. Os canais formais de comunicação por alguma razão não funcionam e as informações oficiais não circulam. Todavia, os canais informais têm incrível agilidade. É necessário ter informações rápidas e precisas sobre os acontecimentos e sobre os companheiros de trabalho que não são divulgadas pelos canais oficiais.

Essa parte eu acho até bom [a rádio corredor], porque tu não tens parceiro fixo na guarda, então o dia em que fores trabalhar com alguém, é bom que saibas a história.

Além disso, a ausência de um plano de carreira que garanta a ascensão sem retrocesso de funções faz com que o receio de hoje ser chefe e amanhã subordinado, gere uma postura mais condescendente. A proteção ao colega é justificada como sendo uma proteção à própria Guarda ou a si mesmo. A cooperação atua nesse momento para acobertar ou remediar uma situação que poderia se tornar mais grave.

Na verdade, quando o guarda está ali pra cuidar da coisa, tens que confiar nele. Infelizmente nem todas as pessoas são confiáveis.

A mobilização subjetiva da inteligência sempre implica em transgressão. Para que o trabalho funcione é necessária a burla, as invenções criativas, caso contrário pode-se incorrer em um funcionamento do tipo "operação-padrão". Os riscos são minimizados pela cooperação entre o coletivo de trabalhadores, que está baseada na confiança, favorecendo a construção de acordos (Dejours, citado por Lancman, 2004). Na prática, para o bom andamento do trabalho, são necessárias burlas e transgressões, embora isso sempre implique em riscos para o trabalhador, pois, em última análise, é dele a responsabilidade e dificilmente o gestor admite ter conhecimento de tais logros engenhosos.

Eu já vi colega colocando a arma numa bota. Arma pequena. Colega que trabalha na noite. E também não sei, talvez fizesse a mesma coisa. O problema é sair no jornal uma denúncia, aí estraga mesmo. Porque se o Brigadiano vir, vai até fazer que não viu, porque é colega, entende.

Uma questão abordada inúmeras vezes nos grupos é quanto à falta de conhecimento da população com relação a GMPA. Essa falta de conhecimento diz mesmo sobre uma falta de reconhecimento do trabalho prestado pela GMPA. Poncioni (2003) aponta que historicamente, no Brasil, tem se atribuído à polícia: "o papel de 'lixeiro da sociedade', cuja tarefa precípua é 'limpar' da sociedade aqueles que, por sua má conduta, criminosa ou não, perturbam a ordem e a paz social" (p. 253).

Ninguém sabe o que é a Guarda Municipal e o que faz. Ninguém sabe. Agora vocês vão receber arma? Estou a vinte e dois anos recebendo salário do senhor e o senhor não sabe o que eu sou e o que eu faço.

Os estudos de Dejours apontam a importância do reconhecimento para a saúde mental do trabalhador. Não é uma reivindicação secundária do trabalhador, mas algo decisivo na dinâmica da subjetividade, no que diz respeito, por exemplo, à chamada motivação para o trabalho. De acordo com Merlo (1999), o reconhecimento é como uma retribuição que o trabalhador espera receber em troca de sua contribuição à organização do trabalho. Contribuição que se dá a partir de sua inventividade, no preenchimento da lacuna entre o trabalho prescrito e o trabalho real. 
O trabalho dos agentes de segurança pública é minado duplamente pela falta de reconhecimento. Por um lado, a sociedade tem um julgamento negativo e preconceituoso. Por outro, dentro das próprias instituições, sofrem com a desvalorização, ficando o reconhecimento ao sabor do chefe do momento, característica do serviço público.

Nesse aspecto, os guardas que exercem as funções de rua são privilegiados, pois se tornam conhecidos, têm maior visibilidade e chegam a receber diretamente $\mathrm{O}$ reconhecimento do público que atendem. Mas o conhecimento da GMPA, que traz o reconhecimento da população também tem seu preço. Não sendo conhecida, a Guarda estava na berlinda, não era alvo de elogios, mas também não era alvo de críticas. $O$ reconhecimento à guarda parece vir pela atuação repressiva e não pela atuação comunitária. Para ter maior visibilidade e ser reconhecido como um agente de segurança diferente das polícias é necessário sair da zona de confronto, buscar maior participação e, portanto, maior exposição.

\section{Considerações finais}

Através da metodologia da psicodinâmica do trabalho foi possível apreender o cotidiano de trabalho da Guarda Municipal em seus aspectos objetivos e subjetivos. Buscamos compreender quais são as implicações da reestruturação da Guarda Municipal de Porto Alegre na dinâmica saúde/adoecimento mental de seus trabalhadores.

Constatamos que o cotidiano de trabalho do guarda municipal em Porto Alegre está permeado pelas mudanças que vêem ocorrendo, principalmente nos últimos cinco anos. Modificações que levam à criação de novas funções e a uma maior visibilidade dos trabalhadores junto a população da cidade.

Há intensa mobilização psíquica entre os guardas, provocada pela peculiaridade do lugar que ocupam hoje em nossa sociedade. Por um lado, pressionadas pela população e pela gestão da PMPA a adotarem uma postura mais proativa na área da segurança urbana. Por outro lado, premidos pela limitação legal de suas atribuições, não sendo reconhecidos constitucionalmente como agentes de segurança pública. Questionam-se até onde podem agir e como deixar de atender às situações que lhes aparecem e não são de sua competência.

Vivenciando uma extensa jornada de trabalho, vêem suas vidas particulares atravessadas pelas características do serviço na segurança. Passam mais tempo no trabalho do que com a família e amigos, o que leva em muitos casos à separação conjugal. Tornam-se mais desconfiados e atentos a tudo e a todos ao seu redor. Ser identificado como agente de segurança significa hoje temer pela própria vida. A vida social e os momentos de lazer também ficam prejudicados pelas características do trabalho em turnos e plantões, principalmente daqueles que trabalham à noite.

Esse funcionamento gera desgaste e adoecimento. Entretanto, são aspectos negados. O adoecimento dificilmente é atribuído ao excesso de trabalho, havendo servidores que preferem trabalhar doentes a tirar licença saúde.

As condições de trabalho enfrentadas pelos guardas municipais são precárias, tanto em termos dos espaços físicos, como de equipamentos. Como resposta, esses trabalhadores fazem uso da inteligência astuciosa e da cooperação, buscando solucionar a falta de equipamentos e os problemas dos ambientes de trabalho com soluções próprias. Elas são não apenas soluções próprias, mas caseiras, como forma de recriar um pouco do ambiente de acolhimento doméstico que usufruem de forma reduzida junto às suas próprias famílias em função das jornadas exaustivas de trabalho. 
Podemos dizer que essa característica é o que garante em parte o funcionamento dos serviços da guarda, caracterizando-se como zelo. Sem essas providências e invenções criativas, o trabalho não seria possível.

O trabalho da Guarda Municipal é percebido por seus integrantes como um trabalho sem produção concreta. Como não exige nenhum material para sua execução, apenas o próprio guarda, a produção parece não ser passível de mensuração. Foco de frustração para os trabalhadores, parece que fazer segurança é não fazer nada.

A guarda carece de uma formação comum, de um plano de carreira e de uma normativa de atuação, bem como de uma definição mais precisa e mensurável dos resultados esperados. A cada concurso realizado os servidores que ingressam recebem um tipo diferente de qualificação. Igualmente pelo número do efetivo e pela dificuldade em mobilizar as pessoas e os recursos necessários para uma formação integral e comum a todos os guardas municipais. É necessário salientar que essa realidade não é exclusividade da GMPA, sendo comum às guardas municipais em geral.

A não existência de um plano de carreira gera insegurança e instabilidade no quadro de chefias. Levando também a um funcionamento em determinados casos de maior tolerância com as transgressões no trabalho.

A cooperação é uma importante estratégia para enfrentar o cotidiano de trabalho. Os vínculos entre os colegas são intensos e muito importantes. Isso porque é essa relação que pode definir entre viver ou morrer em uma ocorrência. A confiança entre os parceiros é destaque necessário.

A serviço desse funcionamento, o fluxo de comunicação na GMPA apresenta algumas peculiaridades. A comunicação formal, oficial é muito lenta e às vezes inexistente. Depende de iniciativas individuais de alguns chefes. Em compensação, a comunicação informal, a chamada "rádio corredor", é muito eficiente.

As atividades desenvolvidas pela GMPA são atividades de risco, ou seja, colocam a vida de seus agentes em perigo. Para confrontar-se no dia-a-dia com essa realidade e retornar ao trabalho no dia seguinte, os guardas lançam mão de mecanismos de defesa, como a negação e o pensamento mágico.

A psicodinâmica do trabalho traz importante contribuição para a discussão saúde mental-trabalho, devido à ênfase não apenas no sofrimento, mas também na relação de prazer possível de ser estabelecida com o trabalho. Além disso, o fato de visar sempre a coletividade e a organização do trabalho mostra-se fundamental, em contraponto às tentativas de individualização e culpabilização do trabalhador pelo adoecimento no trabalho.

Podemos afirmar que a organização do trabalho na GMPA interfere de maneira muito direta na subjetividade de seus servidores. O atual período da Guarda Municipal é efetivamente um tempo de transição. Interfere diretamente na organização do trabalho, na subjetividade e na saúde mental de seus servidores. No sentido de contribuir para a saúde desses trabalhadores, seria importante incrementar os espaços públicos da instituição, ou seja, os espaços de encontro entre os guardas. Dessa maneira, seria possível contribuir para a reflexão do papel da guarda municipal hoje na sociedade e pensar um caminho que pudesse levar à construção de uma guarda cidadã, que se diferencie das polícias por ter identidade própria. Identidade que ainda está por ser construída.

O espaço de fala e de escuta criado pelos encontros em grupo pôde constituir-se em importante aspecto para a reelaboração das estratégias defensivas e para reflexão sobre a organização do trabalho. Nesse sentido, foi construída, em parceria com os guardas municipais, uma proposta de continuidade dos encontros em grupo, que se encontra em andamento, visando um espaço de intervenção. 


\section{Referências}

Amador, F. S. (2002). Violência policial: verso e reverso do sofrimento. Santa Cruz do Sul: Edunisc.

Brasil (1988). Constituição da República Federativa do Brasil.

Dejours, C. (1992). A loucura do trabalho: estudos de psicopatologia do trabalho (5 5 ed.). São Paulo: Cortez e Oboré.

Dejours, C. (2005). A banalização da injustiça social. Rio de Janeiro: Fundação Getúlio Vargas.

Dejours, C. (1999). Conferências brasileiras: identidade, reconhecimento e transgressão no trabalho. São Paulo: Fundap e EAESP/FGV.

Dejours, C. (1986). Por um novo conceito de saúde. Revista Brasileira de Saúde ocupacional, 54 (14), 7-11.

Dias Neto, T. (2005). Segurança urbana: o modelo da nova prevenção. São Paulo: Revista dos Tribunais e Fundação Getulio Vargas.

Guindani, M. (2005). A criação de um novo paradigma em Diadema. In J. T. Sento-Sé (Org.), Prevenção da violência: o papel das cidades. Rio de janeiro: Civilização Brasileira.

Lancman, S. \& Sznelwar, L. I. (Orgs.), Christophe Dejours: da psicopatologia à psicodinâmica do trabalho. Rio de Janeiro: Fiocruz. Brasiléia: Paralelo 15.

Merlo, A. R. C. (1999). A informática no Brasil: prazer e sofrimento no trabalho. Porto Alegre: UFRGS.

Minayo, M. C. de S. \& Souza, E. R. de (Orgs.). (2003). Missão investigar: entre o ideal e a realidade de ser policial. Rio de Janeiro: Garamond.

Ministério da Justiça (2005a). Matriz Curricular Nacional para Guardas Municipais. Brasília: Secretaria Nacional de Segurança Pública.

Ministério da Justiça (2005b). Relatório descritivo: pesquisa do perfil organizacional das guardas municipais. Brasília: Secretaria Nacional de Segurança Pública.

Poncioni, P. (2003). Tornar-se policial: a construção da identidade profissional do policial no Estado do Rio de Janeiro. Tese de Doutorado, Programa de Pós-Graduação em Sociologia, Universidade de São Paulo, São Paulo.

Soares, L. E. (2005). Segurança municipal no Brasil: sugestões para uma agenda mínima. In J. T. Sento-Sé (Org.), Prevenção da violência: o papel das cidades. Rio de janeiro: Civilização Brasileira.

Spode, C. B. (2004). Ofício de oficial: trabalho, subjetividade e saúde mental na polícia militar. Dissertação de Mestrado, Programa de Pós-Graduação em Psicologia Social, Universidade Federal do Rio Grande do Sul, Porto Alegre.

Tittoni, J. (1994). Subjetividade e trabalho: a experiência no trabalho e sua expressão na vida do trabalhador fora da fábrica. Porto Alegre: Ortiz.

\section{Endereço para correspondência:}

tatibaierle@gmail.com 